\title{
Analysis of substrate coverage of hybrid halide perovskite thin films deposited on glass
}

\author{
Jorge Caram $^{1}$, Nicolás Budini ${ }^{1,2}$ \\ Roberto Delio Arce ${ }^{1,2}$
}

\author{
${ }^{1}$ IFIS Litoral (CONICET-UNL), Güemes 3450, 3000 Santa Fe, Santa Fe, Argentina. \\ e-mail: jorge.caram@ifis.santafe-conicet.gov.ar \\ ${ }^{2}$ Facultad de Ingeniería Química, UNL, Santiago del Estero2829, 3000 Santa Fe, Santa Fe, Argentina. \\ e-mail: nicolas.budini@ifis.santafe-conicet.gov.ar; roberto.arce@ifis.santafe-conicet.gov.ar
}

\begin{abstract}
In this work we have studied coverage characteristics of organo-metal lead halide perovskite thin films deposited through the spin-coating technique onto glass substrates that were subjected to different predeposition treatments. Samples were deposited at room temperature using different spinning speeds and two different solvents, namely, dimethylformamide (DMF) and gamma-butyrolactone (GBL). In this way we obtained samples with different characteristics. Characterization of substrate coverage was performed through optical microscopy and we have also performed optical characterization of the deposited films through transmittance measurements. All obtained samples were highly polycrystalline as evidenced from Xray diffraction measurements.
\end{abstract}

Keywords: Solar cell, hybrid perovskite, coverage, susbtrate treatments, spin coating.

\section{INTRODUCTION}

Until some years ago the word "perovskite" was strictly reserved to a family of inorganic materials with a structure similar to that of calcium titanium oxide $\left(\mathrm{CaTiO}_{3}\right)$. These compounds were described as $\mathrm{AMX}_{3}$, being $\mathrm{A}$ and $\mathrm{M}$ two cations and $\mathrm{X}$ the oxygen anion. More recently a big collateral series of perovskites called "halide perovskites" $\left(\mathrm{AMX}_{3}\right)$ have become relevant. In this case the oxygen cations are replaced by halogen cations $(\mathrm{Cl}, \mathrm{Br}, \mathrm{I})$. This series, in turn, may be divided in two groups, namely: alkali-halide perovskites and organo-metal halide perovskites. Around the mid 1990's some authors [1,2,3] reported the detection of good photoelectronic properties in organo-metal halide perovskites. The most relevant organo-

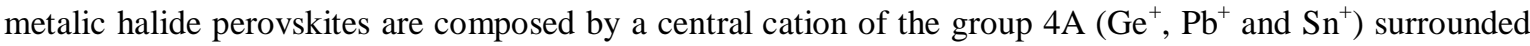
by an octahedron of halogen atoms. The other cation is an organic compound, usually small in size, to keep a cubic geometry of the perovskite structure. Increasing the size of the organic cation may cause a reduction in the dimensionality of the structure. Two organic cations are the most popular until now: formamidinium (FA) $\left(\mathrm{NH}_{2} \mathrm{NH}_{3}\right)$ and methylamonium (MA) $\left(\mathrm{CH}_{3} \mathrm{NH}_{3}\right)$, being the latter more studied.

Solar cells based on organo-metal halide perovskites have a very short but explosive history. In 2009 KOJIMA, et al.[1] published the first paper where these types of perovskites were used as visible light sensitizer in a dye solar cell. The cell was basically a "Grätzel cell" with a $\mathrm{TiO}_{2}$ electrode embedded in $\mathrm{CH}_{3} \mathrm{NH}_{3} \mathrm{PbI}_{3}$, with a liquid electrolyte configuration. The photovoltaic conversion efficiency reported by the Miyasaka group [4] was rather poor, 3.8\%, but it was an incentive in the development of these materials for photovoltaic applications. Optimizing the $\mathrm{TiO}_{2}$ layer, Park et al. were able to produce a jump in the efficiency of the same cell, reaching an efficiency of $6.4 \%$ [1]. The structure of the cell was the same as before and the stability of the cell was as bad as that of the cell prepared by the Miyasaka group. In 2012 several groups started working in solid state sensitized cells based on perovskites, achieving a new outstanding step in efficiency [1]. By the end of 2013, 17.9\% efficiency was reported and certified by NREL. The last part of this history has to do with modifications in the preparation methods of the perovskites and with the architecture of the cell. To date we have reports of efficiencies up to around 20\% [1].

Along the evolution of perovskite solar cells, the architecture of the cell went from the traditional dye sensitized solar cells to planar devices. In planar devices the perovskite constitutes one of the layers of the cell, which is responsible of transporting the photogenerated charge carriers. This fact requires a deeper 
understanding of the basic physics and chemistry around perovskites. Carrier transport mechanism is one of the points to explore in order to improve the quality of the material. Knowing the carrier transport process involves making measurements on the perovskites, isolated from the structure of the cell. The layered cells also need good coverage characteristics of the different layers to make a better use of sunlight. Transport measurements in coplanar geometry also need high coverage of the substrate in order to ensure continuity, and also the geometric factors determinations. For this purpose, solution processing methods seem to be one of the best techniques for fabricating this kind of solar cells because of the low temperatures involved (i.e. low-cost) and its easy scalability to industry manufacture.

For these reasons, in this work we investigate the coverage of the two most used organo-metallic perovskites used in solar cells, $\mathrm{CH}_{3} \mathrm{NH}_{3} \mathrm{PbI}_{3}$ and $\mathrm{CH}_{3} \mathrm{NH}_{3} \mathrm{PbI}_{3-\mathrm{x}} \mathrm{Cl}$, deposited via solution processing under different conditions onto glass substrates, due to their electric insulation properties. The low adherence of precursor solutions on the insulate substrates like polymers, sapphire, quartz and glass, is the main obstacle to overcome. To our knowledge, there are no reports on specific treatments to improve the wettability for substrates used in electrical characterization of films or solar cell. Preliminary probes of wettability lead us to discard substrates of polymethyl methacrylate (PMMA), sapphire $\left(\alpha-\mathrm{Al}_{2} \mathrm{O}_{3}\right)$, and different silicon wafers. Consequently, in the present work we propose some treatments on glass substrates [8,9]. Finally, we also study perovskite coverage over substrates with conductive films used as contacts in solar cells, such as fluordoped tin oxide (FTO) over glass.

\section{MATERIALS AND METHODS}

Both $\mathrm{CH}_{3} \mathrm{NH}_{3} \mathrm{PbI}_{3}$ and $\mathrm{CH}_{3} \mathrm{NH}_{3} \mathrm{PbI}_{3-\mathrm{x}} \mathrm{Cl}_{\mathrm{x}}$ perovskites were prepared from a precursor solution by one step spin-coating process. The precursor solution of $\mathrm{CH}_{3} \mathrm{NH}_{3} \mathrm{PbI}_{3}$ was synthesized by mixing commercial $\mathrm{CH}_{3} \mathrm{NH}_{3} \mathrm{I}\left(0.0087 \mathrm{wt} \%\right.$, Borun New Material Technology LTD) with $\mathrm{PbI}_{2}(0.026 \mathrm{wt} \%$, Cicarelli) at a $1: 1$ molar ratio in gamma-butyrolactone (GBL) as solvent. The mixture was stirred at $60^{\circ} \mathrm{C}$ for $6 \mathrm{~h}$ to ensure a complete dissolution of solutes. In turn, all steps for preparing the $\mathrm{CH}_{3} \mathrm{NH}_{3} \mathrm{PbI}_{3-\mathrm{x}} \mathrm{Cl}_{\mathrm{x}}$ precursor solution were the same, but instead of $\mathrm{PbI}_{2}$ weused $\mathrm{PbCl}_{2}$ (Cicarelli) combined with the MAI in a 3:1 molar ratio. In this case we used N,N-dimethylformamide (DMF) as a solvent. This perovskite solution was prepared in four different concentrations (see Table 1) to study its influence in the substrate coverage.

Soda lime glasses were employed as substrates due to their low conductivity. The glasses were cut in rectangles of $25 \mathrm{~mm} \times 12.5 \mathrm{~mm}$ and cleaned sequentially in an ultrasonic bath at $40^{\circ} \mathrm{C}$ during $20 \mathrm{~min}(10 \mathrm{~min}$ in acetone $+10 \mathrm{~min}$ in isopropyl alcohol) and finally dried under a nitrogen stream. To enhance the glass wettability we proposed two methods: a flaming treatment on the surface and a buffered oxide etch (BOE) $[1,2]$. The former was performed with a pen style butane gas torch, flaming the glass surface only once to avoid crashing the substrate, just before dispensing the precursor solution. The latter consisted of a $2 \mathrm{~min}$ etching in a solution of hydrofluoric acid $(49 \% \mathrm{HF})$ buffered with ammonium fluoride $\left(40 \% \mathrm{NH}_{4} \mathrm{~F}\right)$ at a1:10 volume ratio.

Table 1: Concentrations of the precursor solution of $\mathrm{MAI}: \mathrm{PbCl}_{2}$ (3:1 molar ratio) in DMF, employed to study the perovskite film coverage.

\begin{tabular}{c|c}
\hline LABEL & CONCENTRATION \\
\hline $\mathrm{x} 1$ & $(0.9: 0.3) \mathrm{M}$ \\
\hline $\mathrm{x} 2$ & $(1.8: 0.6) \mathrm{M}$ \\
\hline $\mathrm{x} 3$ & $(2.7: 0.9) \mathrm{M}$ \\
\hline $\mathrm{x} 4$ & $(3.6: 1.2) \mathrm{M}$ \\
\hline
\end{tabular}

The perovskite films were prepared by spin-coating of the substrates glasses with the precursor solutions under nitrogen atmosphere. We used three different spinning speeds (1000, 2000 and $3000 \mathrm{rpm})$ to evaluate the influence on coverage characteristics. A volume of $80 \mu \mathrm{L}$ of precursor solution was dispensed duringa $4 \mathrm{~s}$ interval at 500rpm and then the final speed was maintained for $20 \mathrm{~s}$. Some of the samples were subjected to a second process, consisting of a dripping with toluene to improve the perovskite film homogeneity [3]. For this, $60 \mu \mathrm{L}$ of toluene was dispensed just $5 \mathrm{~s}$ before the spin-coating program ended. The crystallization was achieved by annealing the films at $85^{\circ} \mathrm{C}$ for 10 min into a sealed reactor under nitrogen flow. During this process the films showed a transformation, starting with yellow color, adopting a red-brown color after some minutes of annealing and finally taking a dark grey color.

Perovskites films were characterized by X-ray diffraction (XRD) and high resolution optical 
microscopy. The images obtained from the microscope were evaluated with a standard image processing software. All images were acquired in transmission mode and bright field illumination to enhance contrast between perovskite structures and glass substrate. Coverage was calculated over images, after converting them to binary matrices, as the number of dark pixels divided to the total amount of pixels. Each coverage value was obtained as the average of three different images of the same sample. The uncertainty of this method comes mainly from the thresholding method. Therefore, different thresholding methods were adopted to evaluate the uncertainty. In this way, discrepancies between extreme cases did never exceed $5 \%$.

\section{RESULTS}

The perovskite structure in the synthesized samples was confirmed by XRD measurements (see Figure 1). XRD patterns show characteristic peaks of perovskite-type tetragonal lattice. Perovskites prepared using GBL as solvent presented an amorphous phase and some traces of $\mathrm{PbI}_{2}$ (Figure 1a).Perovskites derived from DMF solution showed a cleaner pattern with sharper peaks, which implies larger grain sizes (Figure 1b). In this case, the intensity relations did not agree with powder perovskite patterns, revealing a preferential orientation. The patterns were indexed from reference patterns extracted from the literature $[3,4]$. Transmittance measurements reveal the expected behavior, with a great absorption in the visible range, for wavelengths less than $760 \mathrm{~nm}$, as can be seen in Figure 2. This is in accordance with previously reported value of the $\sim 750 \mathrm{~nm}$ for the characteristic absorption edge of $\mathrm{CH}_{3} \mathrm{NH}_{3} \mathrm{PbI}_{3-x} \mathrm{Cl}_{x}\left(\right.$ and $\left.\mathrm{CH}_{3} \mathrm{NH}_{3} \mathrm{PbI}_{3}\right)$ [1]

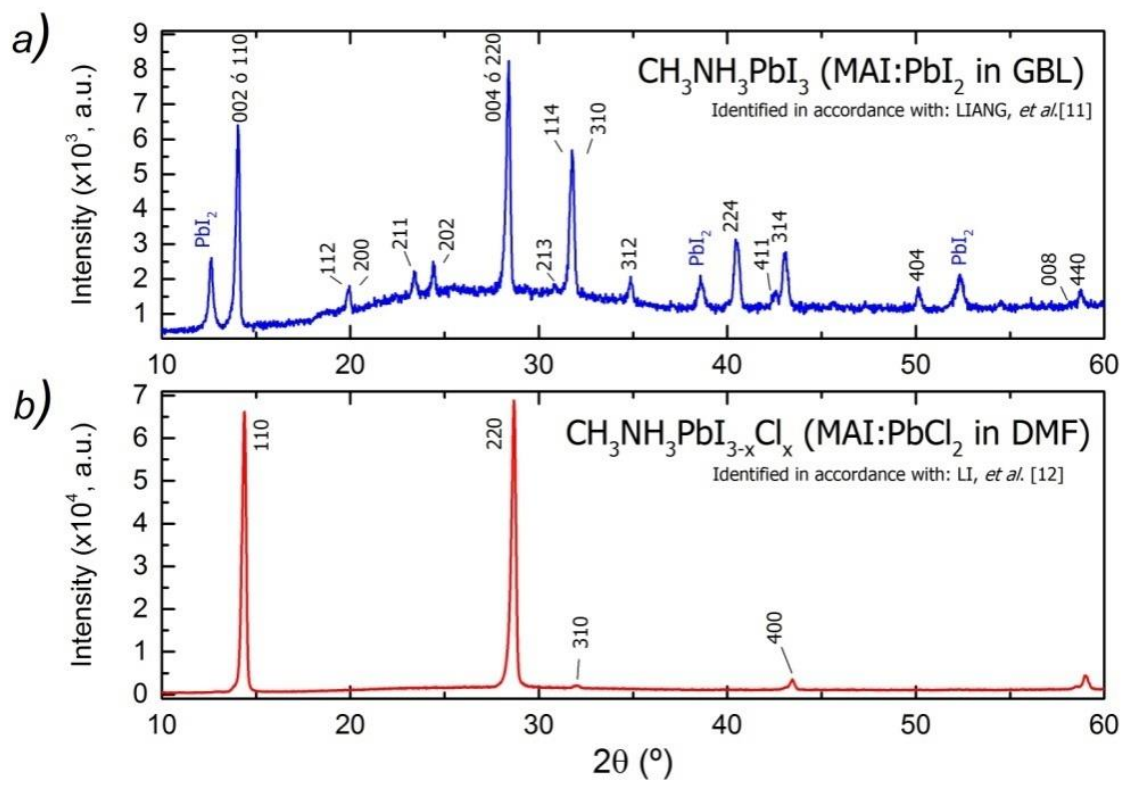

Figure 1: $\mathrm{XRD}$ patterns of both synthesized perovskites: (a) $\mathrm{CH}_{3} \mathrm{NH}_{3} \mathrm{PbI}_{3}$ (from GBL) and,(b) $\mathrm{CH}_{3} \mathrm{NH}_{3} \mathrm{PbI}_{3-x} \mathrm{Cl}_{x}$ (from DMF). In contrast with the former, the latter resulted in a contaminant free, negligible amorphous phase and sharper peaks pattern.

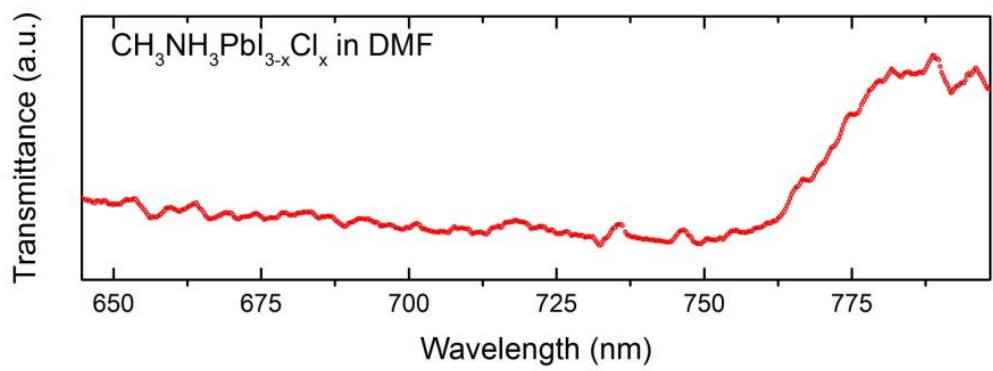

Figure 2: Transmittance measurement (linear scale) showing the characteristic absorption edge ofCH $\mathrm{NH}_{3} \mathrm{PbI}_{3-\mathrm{x}} \mathrm{Cl}_{\mathrm{x}}$ between 750 and $780 \mathrm{~nm}$.

The lack of adherence of the precursor solution on glass was the first problem to solve during the preparation of the films. To overcome this problem we tried different paths. In all cases, the best results were 
obtained using a buffered oxide etch of HF (2 min). This is a method widely used to etch silicon dioxide in integrated circuit technologies [9]. A remarkable result can be appreciated in Figure 3, where part of the substrate was treated with BOE and the other with common cleaning method (acetone/isopropyl alcohol). Substrate coverage ranged from $0 \%$ to $50 \%$ approximately, with BOE pre-treatment.

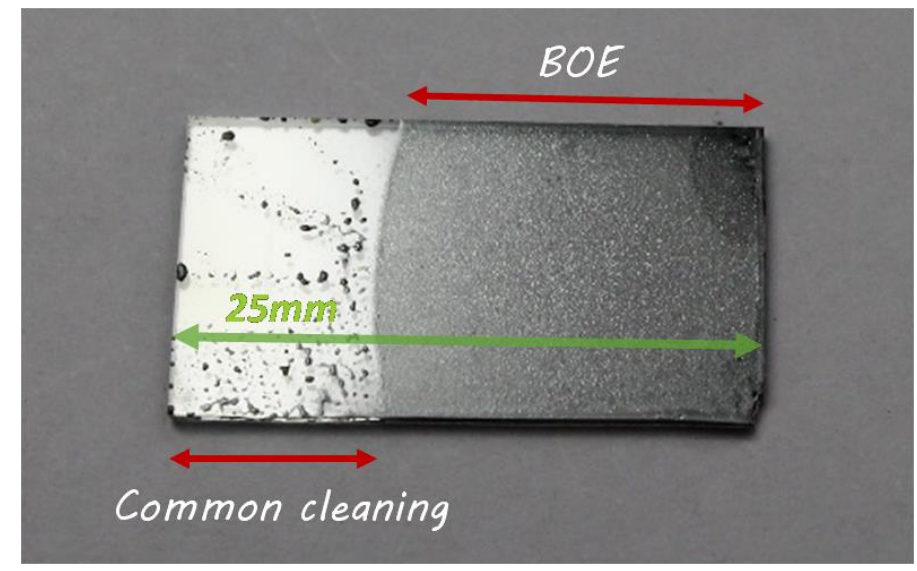

Figure 3: Remarkable effect of the BOE attack to improve substrate wettability.

It is well known that the spinning speed during spin-coating has a direct influence on film thickness and, therefore, on coverage.

Figure 4 shows the coverage and characteristic size of the $\mathrm{CH}_{3} \mathrm{NH}_{3} \mathrm{PbI}_{3-x} \mathrm{Cl}_{x}$ particles constituting the deposited film for three different speeds, at fixed solution concentration. Substrate was cleaned and pretreated with BOE solution as described above. The width of the particle size distribution is represented by the error bars of the characteristic size. We take this parameter to quantify the degree of homogeneity of the film. Between 1000 and $2000 \mathrm{rpm}$ there was no significant improvement on the coverage, but the homogeneity observed (error bars) in the samples was better at 2000rpm. The coverage underwent a slight diminution at $3000 \mathrm{rpm}$, as expected for higher rotational speeds. The characteristic size of the deposited particles decreased at higher speeds. However, the size distribution at $2000 \mathrm{rpm}$ is sharper, as shown by the error bars. This evidences that thi:

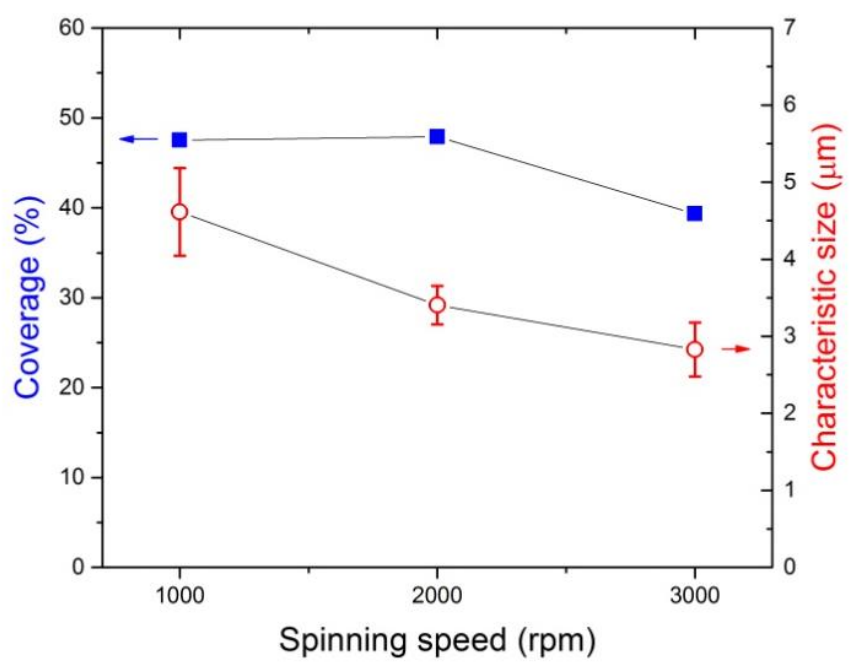

ilm.

Figure 4: Substrate coverage (blue squares) and characteristic grain size (red circles)as a function of the spinning speed. Error bars represent the width of the particle size distribution.

We also studied the influence of the solution concentration (Table 1) on the degree of coverage, in BOE pre-treated substrates. We found that the coverage increased monotonically with concentration, as can be observed in Fig. 5, changing considerably (by a factor of 3 ) between the lowest $(\times 1)$ and the highest $(\times 4)$ concentrations. The characteristic size of the deposited particles showed a similar behavior, showing a 
maximum value for the highest concentration (3.6 MAI:1.2 $\mathrm{PbCl}_{2}$ molar ratio).

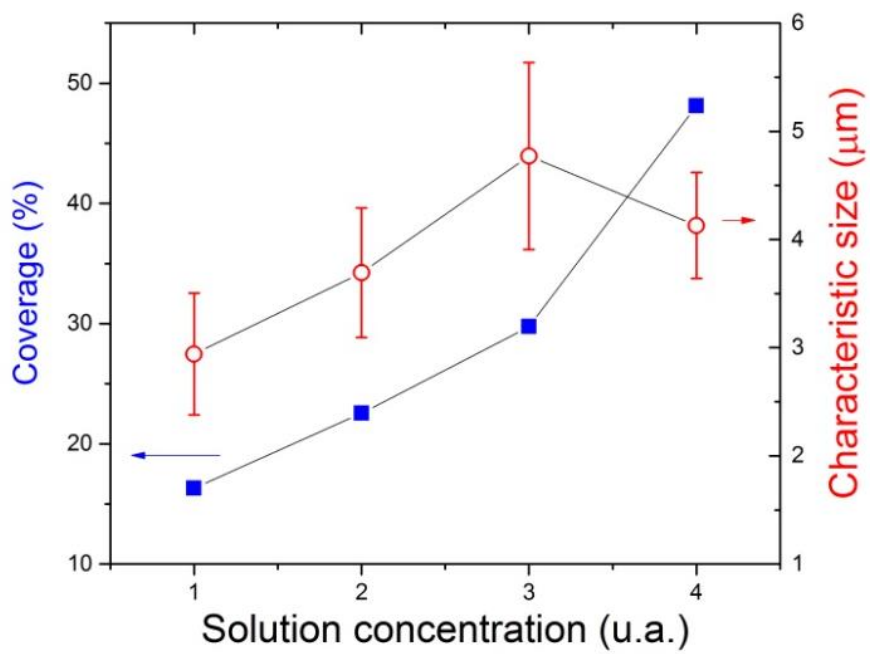

Figure 5: Coverage (blue squares) and characteristic grain size (red circles) against concentration of the precursor solution. Coverage shows a strong dependence on concentration. Characteristic size behaves similarly to coverage but shows a maximum value for $\times 4$ concentration (3.6 MAI: $1.2 \mathrm{PbCl}_{2}$ molar ratio).Substrates with BOE pre-treatment.

We explored several alternatives to improve the glass substrate coverage while keeping the concentration and spinning speed fixed. As mentioned before, the surface hydrophilization was achieved by two means: a flaming method and a chemical one (BOE). No major differences were observed when comparing both methods (see Figure 6). We also explored a toluene dripping method on a substrate previously treated with BOE solution for 2 min, which improved coverage in almost $10 \%$. We prepared also perovskite films on FTO/glass substrates, without (67\%) and with (74\%) toluene method. The characteristic particle size seemed to follow a similar trend as that of the coverage, as it is shown in Figure 6.

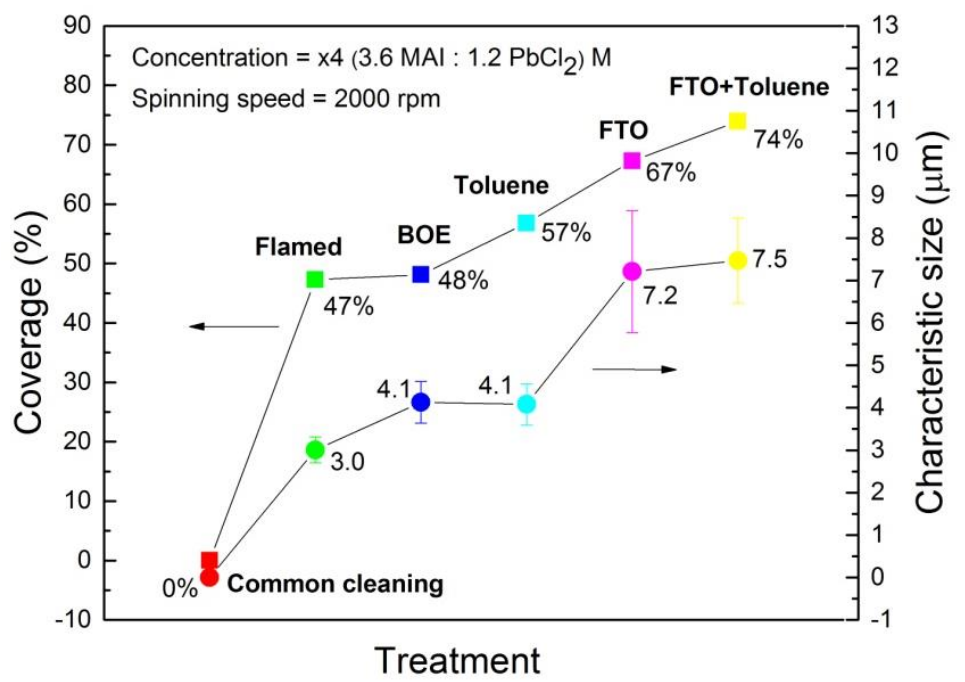

Figure 6: Substrate coverage (left axis) and characteristic particle size (right axis)for different treatments.

High resolution images obtained from optical microscopy are shown in Figure7. Each of them corresponds to the different substrate pretreatment methods (excluding the common one) of Figure 6. The deposited particles possessed a nearly cubic shape and they were observed more overlapped as coverage increased. A typical distribution of characteristic particle size is presented in Figure 7f, this histogram was obtained from the image shown in Figure 7d, that corresponds to a perovskite film deposited onto a FTO substrate. A unimodal distribution means we obtained just one grain population with sizes randomly distributed around an average value, demonstrating a unique stage of crystallization. Due to the nearly cubic shape of the observed particles, an approximation of the film thickness could be inferred from average particle size. Thus, for different samples, the thickness could range from 2 to $8 \mu \mathrm{m}$. From this approach, the 
film thickness shows just a slightly dependence on the spinning speed (Figure 4).
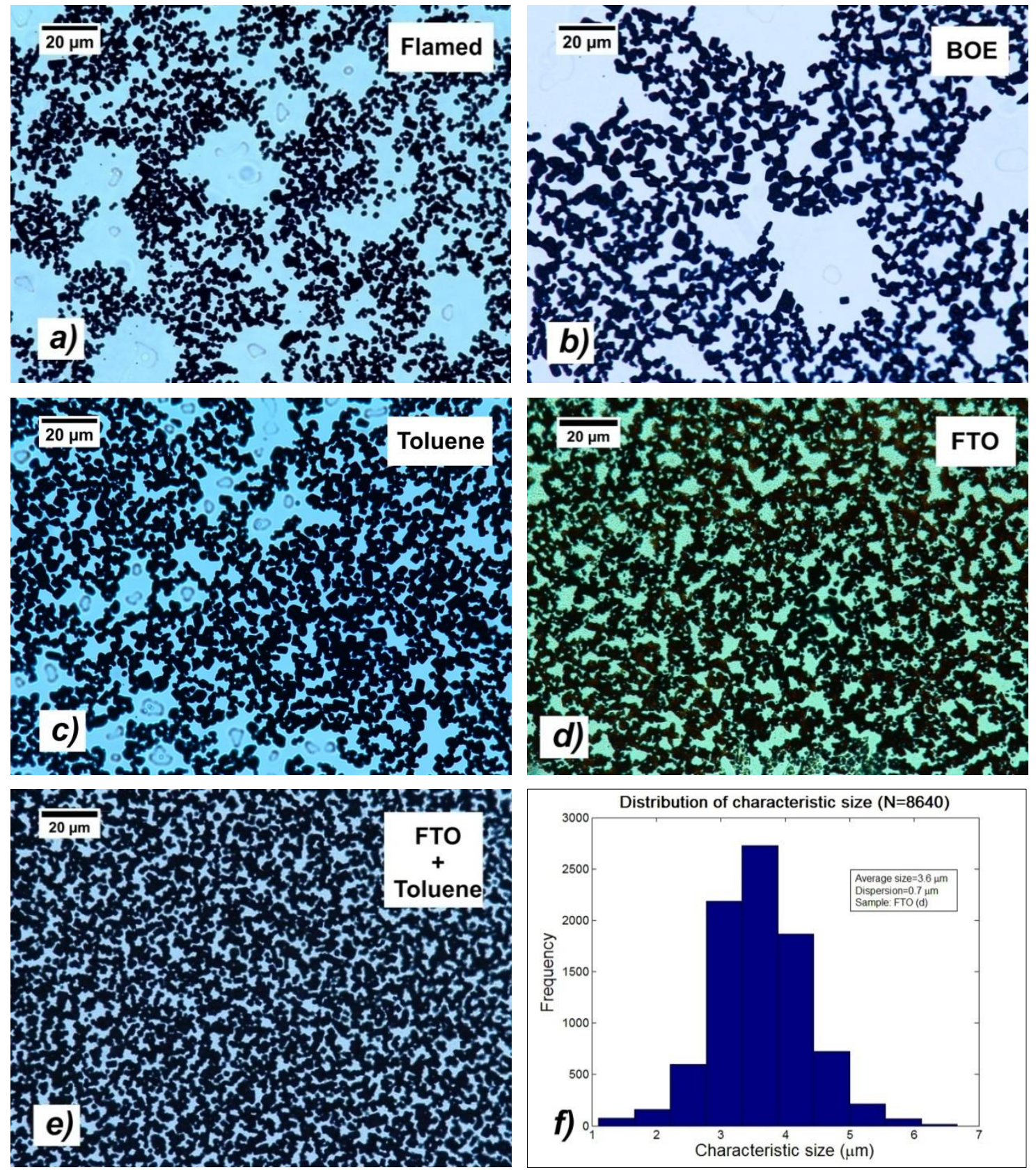

Figure 7: High resolution optical microscopy images of the perovskite films deposited with different substrate pretreatments:(a) flamed substrate; (b) substrate treated with BOE (HF) solution; (c) substrate treated with BOE and toluene dripping; (d) perovskite deposited onto FTO substrate;(e) perovskite deposited onto FTO substrate treated with toluene dripping; (f) particle size distribution obtained from (d).

\section{DISCUSSION}

We have obtained perovskite samples using the spin-coating procedure. For both starting solution, $\mathrm{CH}_{3} \mathrm{NH}_{3} \mathrm{I}: \mathrm{PbI}_{2}$ (1:1) en GBL o (3:1) $\mathrm{CH}_{3} \mathrm{NH}_{3} \mathrm{I}: \mathrm{PbCl}_{2}$ in $\mathrm{DMF}$, we were able to obtain organo-metal perovskites with a tetragonal structure. We have found that higher crystallinity was obtained for samples where the iodine atoms were partially replaced by $\mathrm{Cl}$. Also, the $\mathrm{Cl}^{-}$doped samples did not show wastes as in the case of pure iodine perovskites. The presence of sharper peaks in the XRD patterns of $\mathrm{Cl}$ doped perovskites accounts for the existence of larger crystals in the deposited films. Larger grain sizes in the films are desirable, since transport properties will be dependent on structural defects. In coincidence with this, COLELLA, et al [13] has reported that the presence of $\mathrm{Cl}^{-}$dramatically improves the charge transport properties of the perovskites. An improvement in the transport properties is reflected in a remarkable increase in the conversion efficiency of photovoltaic devices based on these films [13]. 
The study of coverage is essential for the manufacture of photovoltaic and optoelectronic devices, and even for the basic study of these materials such as transport properties and optical properties. In particular, we have found scarce publications dedicated to conductivity measurements, probably due to the difficulty of obtaining films with a high degree of coverage on insulating substrates like glass. Our results show that it is possible to achieve important coverage improvements through the use of surface flaming and chemical etching with BOE. The final result did not seem to be very different when comparing both methods. However, with the flaming technique it is not easy to achieve a homogeneous treatment of the surface. In addition, its use may generate strain on the substrate leading to potential ruptures. The use of BOE solution, instead, allows for greater uniformity in the treatment of the surface and ensures a good reproducibility in all the samples.

The basic reaction of the glass with HF is given by the following equation [9]:

$$
\mathrm{SiO}_{2}+6 \mathrm{HF} \rightarrow \mathrm{H}_{2} \mathrm{SiF}_{6(\text { liq })}+2 \mathrm{H}_{2} \mathrm{O}
$$

The role of $\mathrm{NH}_{4} \mathrm{~F}$ in the solution is to keep the $\mathrm{pH}$ constant to guarantee a stable and controlled etch rate. Solution acts on the surface of the glass, even inside the native surface microcracks of the substrate. Under BOE etch, those microcracks are slightly opened and act as crystal nucleation centers. We found that etching times larger than 2 min do not produce higher coverage, probably because of those microcracks become smoother.

Coverage showed a moderate dependence on spinning speed, with an optimum speed at $2000 \mathrm{rpm}$. On the other hand, a strong influence of concentration was found. Nevertheless, no improvements can be obtained with higher concentrations. This is due to the fact that $\mathrm{x} 4$ concentration was prepared at the limit of solubility of the compounds in DMF.

Toluene dripping method showed to be an additional way to improve the coverage. As described in the literature [10], a drop of toluene (miscible in DMF) is dispensed during spin-coating program; all compounds are frozen in a uniform layer, forming a new complex which acts as an intermediate phase. By annealing that complex it becomes a crystalline and uniform perovskite. This method was also applied on FTO substrate, taking additional advantage of texturized surface of FTO substrate, with successful results as can be seen in Figure 6 and Figure 7f.

The cubic shape of the characteristic structures allowed us to estimate the film thickness, with values range from 2 to $8 \mu \mathrm{m}$ for different samples. In particular, no significant dependence on the spinning speed was observed. We suppose the spinning speed will start to influence the thickness only with coverages close to $100 \%$.

\section{CONCLUSIONS}

In summary, we have studied the coverage characteristics of organo-metal lead halide perovskite thin films deposited through the spin-coating technique onto glass substrates. In order to obtain samples with different coverage characteristics we used two different substrates, glass and glass covered with FTO subjected to different pre-deposition treatments, different spinning speeds during deposition and two different solvents, DMF and GBL, in the precursor solutions. We found that the optimum spinning speed for deposition was $2000 \mathrm{rpm}$ and we chose this value to analyze the influence that different substrate pretreatment methods have on substrate coverage. All obtained samples were highly polycrystalline, as could be evidenced from XRD measurements, and a preferential orientation of growth was observed when using DMF. Besides this, perovskites obtained from the DMF solution presented a sharper XRD pattern, implying larger crystalline grain sizes in their structure. The deposited films were composed of particles with average sizes between 2 and $8 \mu \mathrm{m}$ and coverage seems to show a correlation with particle size. The thickness was estimated in the range of 2 to $8 \mu \mathrm{m}$, showing no significant dependence on spinning speed. With respect to common cleaning (sonication with acetone and isopropyl alcohol) of glass substrates we observed that flaming improved considerably the coverage. However, BOE and toluene cleaning yielded an even better coverage. Moreover, FTO substrates evidenced a higher coverage, which increased even more after being pretreated with toluene. We achieved significant improvements towards higher coverage on insulating and conductive substrates, which can be used in electrical measurements and solar cells. Several aspects of preparation of perovskite precursor solutions, deposition, and post-deposition treatments still require further research to obtain stable perovskite films suitable for photovoltaic devices. 


\section{BIBLIOGRAPHY}

[1] MITZI, D. B. "Synthesis, Crystal Structure, and Optical and Thermal Properties of (C4H9NH3)2MI4 (M $=\mathrm{Ge}, \mathrm{Sn}, \mathrm{Pb})$ ", Chemistry of Materials, v. 8, n. 3, pp. 791-800, Jan. 1996.

[2] PAPAVASSILIOU, G. C., KOUTSELAS, I. B. "Structural, optical and related properties of some natural three- and lower-dimensional semiconductor systems", Synthetic Metal, v. 71, n. 1, pp. 1713-1714, 1995.

[3] CALABRESE, J., JONES, N. L., HARLOW, R. L., et al., "Preparation and characterization of layered lead halide compounds", Journal of the American Chemical Society, v. 113, n. 6, pp. 2328-2330, 1991.

[4] KOJIMA, A., TESHIMA, K., SHIRAI, Y., et al., "Organo metal halide perovskites as visible-light sensitizers for photovoltaic cells", Journal of the American Chemical Society, v. 131, n. 17, pp. 6050-6051, Apr. 2009.

[5] IM, J.-H, LEE, C.-R., LEE, J.-W., et al., “6.5\% efficient perovskite quantum-dot-sensitized solar cell,” Nanoscale, v. 3, n. 10, pp. 4088-4093, 2011.

[6] LEE, M. M., TEUSCHER, J., MIYASAKA, T., et al., "Efficient Hybrid Solar Cells Based on MesoSuperstructured Organometal Halide Perovskites", Science, v. 338, n. 6107, pp. 643-647, 2012.

[7] SERVICE, R. F. "Perovskite Solar Cells Keep On Surging", Science, v. 344, n. 6183, 2014.

[8] RYNTZ, R. A. "Coating adhesion to low surface free energy substrates", Prog. Org. Coatings, v. 25, n. 1, pp. 73-83, 1994.

[9] SPIERINGS, G. A. C. M. "Wet chemical etching of silicate glasses in hydrofluoric acid based solutions," Journal of Material Science, v. 28, pp. 6261-6273, 1993

[10] JEON, N. J., NOH, J. H., KIM, Y. C., et al., "Solvent engineering for high-performance inorganicorganic hybrid perovskite solar cells", Nature Materials, v. 13, n. July, pp. 1-7, 2014.

[11] LIANG, K., MITZI, D. B., PRIKAS, M. T. "Synthesis and Characterization of Organ-

ic-InorganicPerovskiteThinFilmsPreparedUsing a Versatile Two-Step Dipping Technique," Chemistry of Materials, v. 10, n. 1, pp. 403-411, 1998.

[12] LI, Y., SUN, W., YAN, W., et al., "High-Performance Planar Solar Cells Based On CH3NH3PbI3-xClx Perovskites with Determined Chlorine Mole Fraction", Advanced Functional Materials, v. 25, n. July, pp. 4867-4873, 2015.

[13] COLELLA, NS., MOSCONI, E., FEDELI, P., et al., "MAPbI3-xClx Mixed Halide Perovskite for Hybrid Solar Cells: The Role of Chloride as Dopant on the Transport and Structural Properties", Chemistry of Materials, v. 25, n. 22, pp. 4613-4618, 2013. 